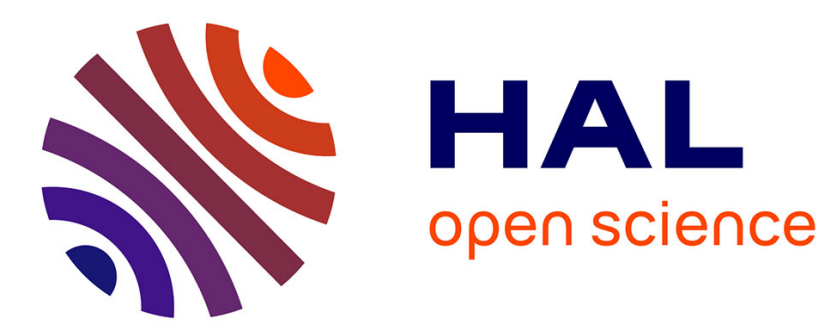

\title{
Management of a Hybrid Fuel Cell System Using a Predictive Control Approach
}

\author{
Catherine Cadet, Bogdan Robu
}

\section{To cite this version:}

Catherine Cadet, Bogdan Robu. Management of a Hybrid Fuel Cell System Using a Predictive Control Approach. ICSTCC 2015 - 19th International Conference on System Theory, Control and ComputingJoint Conference SINTES 19, SACCS 15, SIMSIS 19, Oct 2015, Cheile Gradistei, Romania. pp.484489, 10.1109/ICSTCC.2015.7321340 . hal-01239851

\section{HAL Id: hal-01239851 \\ https://hal.science/hal-01239851}

Submitted on 12 Mar 2019

HAL is a multi-disciplinary open access archive for the deposit and dissemination of scientific research documents, whether they are published or not. The documents may come from teaching and research institutions in France or abroad, or from public or private research centers.
L'archive ouverte pluridisciplinaire HAL, est destinée au dépôt et à la diffusion de documents scientifiques de niveau recherche, publiés ou non, émanant des établissements d'enseignement et de recherche français ou étrangers, des laboratoires publics ou privés. 


\title{
Management of a Hybrid Fuel Cell System Using a Predictive Control Approach
}

\author{
Catherine Cadet, Bogdan Robu \\ Univ. Grenoble Alpes, GIPSA-Lab \\ CNRS, GIPSA-Lab \\ F-38000 Grenoble, France \\ Catherine.cadet@gipsa-lab.grenoble-inp.fr, Bogdan.Robu@gipsa-lab.grenoble-inp.fr
}

\begin{abstract}
The objective of this work is to improve the power management subsystem of a hybrid fuel cell / supercapacitor power generation system. The predictive approach is a relevant available control strategy that can explicitly handle constraints including soft ones and that can also deal with multiple control inputs. Some improvements are presented to shorten the computation time which is very important in practical cases. The first results show the interest of the proposed approach and the possible improvements.
\end{abstract}

Keywords-Predictive Control, Fuel Cells, Supercapacitors

\section{INTRODUCTION}

Fuel cells convert the reactant's chemical energy directly into electrical and thermal energies with high efficiency and good environmental compatibility. Proton Exchange Membrane Fuel Cell (PEMFC) is well known as an efficient and eco-friendly power source, but unfortunately it offers slow dynamics. When attached as primary energy source in a vehicle, fuel cell would thus not be able to respond to abrupt load variations. Supplementing supercapacitor to the system provides a solution to this shortcoming.

Many power electronic architectures have been associated to hybrid power sources. In this study, the fuel cell is associated with a supercapacitor in order to face the high current demand and fast load changes. A two-converter parallel structure associating a static converter (supercondensator) and a PEM Fuel Cell, with two converters is used. This structure leads to a good controllability, as each power source has its own control variable [1].

The control objectives are of two types: the first one is to ensure the power demand of the load and the second one is to mitigate harmful current transients of the fuel cell for which it may be in risk of oxygen starvation and overheating problems. That finally increases the lifespan of the fuel cell.

Several control laws have been proposed recently. References [2] and [3] highlight a contradiction in the approaches of the control strategy to be developed: on one hand the system management requires an advanced control approach, but on the other hand the PID is still a standard industrial controller solution at present, and will continue to be compared to various novel forms of voltage controllers. A robust approach has been proposed by [6], but the drawbacks are the difficulties to handle constraints and non-linearities. However in this application, the constraints are a good way to ensure no damage of the fuel cell. To overcome these difficulties, the MPC approach is a good candidate which has also been proposed in literature [4] [5].

In this article, an improved NMPC control law is developed to better fit industrial requirements while maintaining good knowledge on the complex behavior of the system. This control law is applied on a Fuel Cell system composed by a PEMFC of $500 \mathrm{~W}$ associated with a $58 \mathrm{~F}$ supercapacitor (SC) [6].

The paper is organized as follows. In Section 2, the hybrid fuel cell / supercapacitor and the model of the system are described. The proposed control strategy is presented in Section 3. In Section 4, two controllers are carried out: a classical NMPC controller and the proposed one. Conclusions are given in Section 5 .

\section{STUDIED SYSTEM}

\section{A. Electrical hybrid system : fuel cell / supercapacitor}

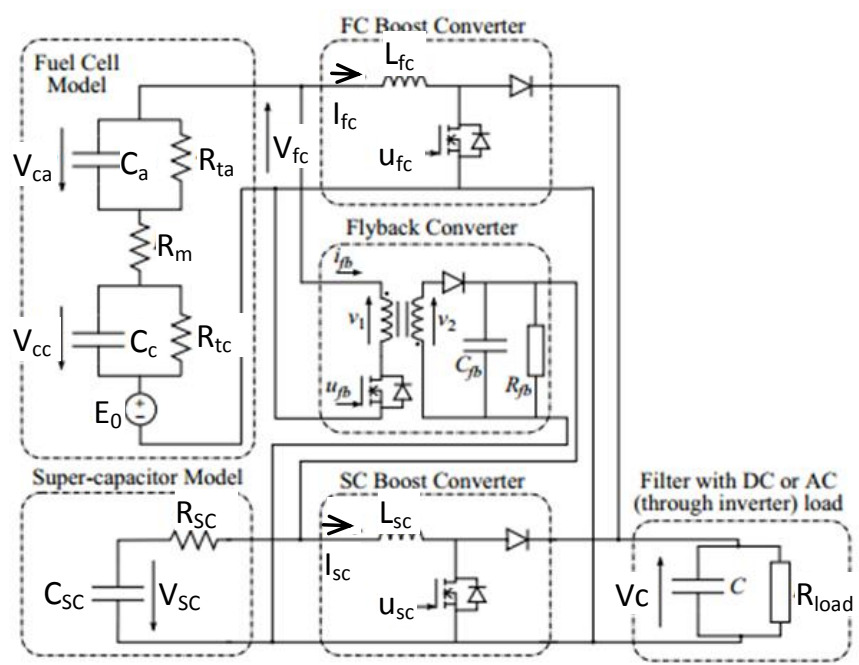

Fig. 1. Hybrid power generation studied system. 
Figure 1 shows the electrical hybrid system. It consists of a fuel cell, used as the main source, through a current nonreversible $\mathrm{dc}-\mathrm{dc}$ boost converter and a supercapacitor used as an auxiliary source, which is connected to the dc link through dc-dc boost converter, and the load [6]. The supercondensator converter (SC) is not reversible, this means that the SC recharge from Fuel Cell (FC) current is assured by a third converter, a flyback converter. The flyback however, is controlled independently from the boost converters and is not considered in this study. The SC current can be positive or negative, allowing energy to be transferred in both directions.

A non-linear model of the switching system is given by the following set of equations [6]:

$$
\begin{gathered}
\dot{\mathrm{V}}_{\mathrm{cc}}=\frac{1}{\mathrm{Cc}}\left(\mathrm{I}_{\mathrm{fc}}-\frac{\mathrm{V}_{\mathrm{cc}}}{\mathrm{R}_{\mathrm{tc}}}\right) \\
\dot{\mathrm{V}}_{\mathrm{ca}}=\frac{1}{\mathrm{Ca}}\left(\mathrm{I}_{\mathrm{fc}}-\frac{\mathrm{V}_{\mathrm{ca}}}{\mathrm{R}_{\mathrm{ta}}}\right) \\
\dot{\mathrm{I}}_{\mathrm{fc}}=\frac{1}{\mathrm{~L}_{\mathrm{fc}}}\left[\mathrm{E}_{0}-\mathrm{V}_{\mathrm{ca}}-\mathrm{V}_{\mathrm{cc}}-\left(\mathrm{R}_{\mathrm{m}}+\mathrm{R}_{\mathrm{load}}\right) \mathrm{I}_{\mathrm{fc}}-\left(1-\alpha_{\mathrm{fc}}\right) \mathrm{V}_{\mathrm{c}}\right] \\
\dot{\mathrm{I}}_{\mathrm{sc}}=\frac{1}{\mathrm{~L}_{\mathrm{sc}}}\left[\mathrm{V}_{\mathrm{sc}}-\mathrm{R}_{\mathrm{sc}} \mathrm{I}_{\mathrm{sc}}-\left(1-\alpha_{\mathrm{sc}}\right) \mathrm{V}_{\mathrm{c}}\right] \\
\dot{V}_{s c}=\frac{1}{C} I_{s c} \\
\dot{\mathrm{V}}_{\mathrm{c}}=\frac{1}{\mathrm{C}}\left[\left(1-\alpha_{\mathrm{fc}}\right) \mathrm{I}_{\mathrm{fc}}+\left(1-\alpha_{\mathrm{sc}}\right) \mathrm{I}_{\mathrm{sc}}-\mathrm{I}_{\text {load }}\right]
\end{gathered}
$$

where $\mathrm{V}_{\mathrm{C}}$ is the DC bus voltage, $\mathrm{I}_{\mathrm{fc}}$ and $\mathrm{I}_{\mathrm{sc}}$ are the FC and SC currents, Vcc and Vca are the double layer capacitor voltages in the cathode and anode respectively, $\mathrm{V}_{\mathrm{sc}}$ is the $\mathrm{SC}$ voltage. The system inputs $u(t)$ are given by the angles $\alpha_{\mathrm{fc}}$ and $\alpha_{\mathrm{sc}}$, the average values of the switching functions of the FC and SC power converters, $u_{\mathrm{fc}}$ and $\mathrm{u}_{\mathrm{sc}}$. The load current $\mathrm{I}_{\mathrm{load}}$ is considered as the system output disturbance $w(t)$.

The system parameters are given in Table I for a $500 \mathrm{~W}$ PEMFC with a nominal DC bus output voltage at $24 \mathrm{~V}$. The nominal values are given in Table II for a steady-state equilibrium point.

For the ongoing sections, only the electrical performances on the DC bus are considered. The thermodynamics control is then assumed to be perfect (oxygen and hydrogen pressures are constant).

\section{B. Model simulations}

Firstly, some simulations on the model are realized in order to test its behavior. We mostly check the controllability and estimate the different response times for the fuel cell and the supercapacitor.

The effect of a load step on the $\mathrm{I}_{\text {load }}$ current has firstly been simulated and the results are shown in Figure 2. The step has been taken $50 \%$ above the nominal value.
TABLE I. SYSTEM PARAMETERS

\begin{tabular}{|l|c|c|}
\hline \multicolumn{1}{|c|}{ Parameter } & Value & Units \\
\hline $\mathrm{E}_{0}$ & 13.4 & Volts \\
\hline $\mathrm{Rm}$ & 1.28 & $\mathrm{~m} \Omega$ \\
\hline $\mathrm{Rtc}$ & 2.04 & $\mathrm{~m} \Omega$ \\
\hline $\mathrm{Rta}$ & 0.47 & $\mathrm{~m} \Omega$ \\
\hline $\mathrm{Ca}=\mathrm{Cc}$ & 2.12 & $\mathrm{~F}$ \\
\hline $\mathrm{Csc}$ & 58 & $\mathrm{~F}$ \\
\hline $\mathrm{Rsc}$ & 1.9 & $\mathrm{~m} \Omega$ \\
\hline $\mathrm{Lfc}=\mathrm{Lsc}$ & 50 & $\mu \mathrm{H}$ \\
\hline $\mathrm{C}$ & 18.8 & $\mathrm{mF}$ \\
\hline
\end{tabular}

TABLE II. STEADY-STATE EQUILIBIRUM VALUES

\begin{tabular}{|c|c|c|c|c|c|c|c|}
\hline $\boldsymbol{V} \boldsymbol{c c}$ & $\boldsymbol{V} \boldsymbol{c a}$ & $\boldsymbol{I f c}$ & $\boldsymbol{I s c}$ & $\boldsymbol{V} \boldsymbol{s} \boldsymbol{V}$ & $\boldsymbol{V c}$ & $\boldsymbol{\alpha}_{\boldsymbol{f c}}$ & $\boldsymbol{\alpha}_{\boldsymbol{s c}}$ \\
\hline 73 & 17 & 36 & 0 & 14.6 & 23.8 & 0.44 & 0.39 \\
$\mathrm{mV}$ & $\mathrm{mV}$ & $\mathrm{A}$ & $\mathrm{A}$ & $\mathrm{V}$ & $\mathrm{V}$ & & \\
\hline
\end{tabular}

Here, the expected behavior of each component is visible: the fuel cell current is increasing progressively until the new steady-state value while the supercapacitor supplies the fuel cell current during transient periods.
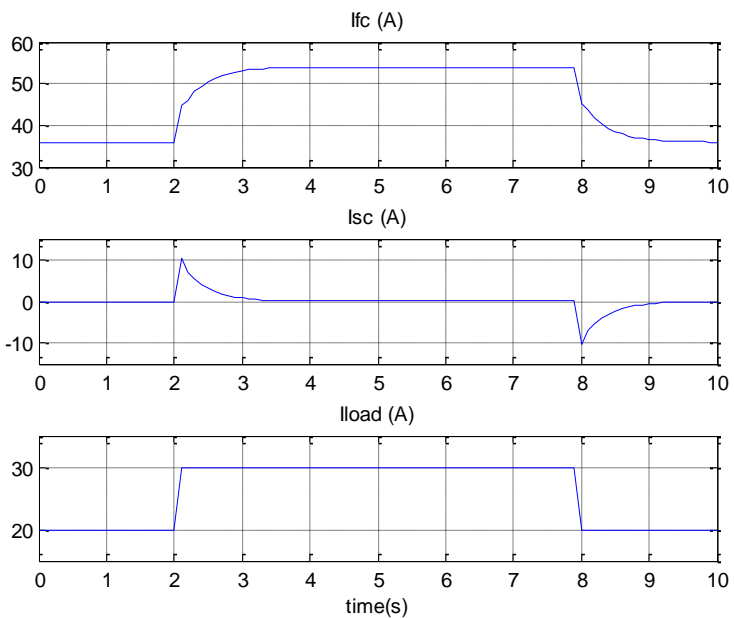

Fig. 2. Response time of fuel cell on a current load

A step on the actuator $\alpha_{\mathrm{fc}}$ has also been simulated and the results are shown in Figure 3. The magnitude of the step is $50 \%$ above the nominal value. The voltage $\mathrm{Vc}$ is sensitive to the actuator approximately in the same proportions (increase about $17 \%$ ). The time response is about 1 second.

The effect of a step on the actuator $\alpha_{\mathrm{sc}}$ is shown in Figure 4. The magnitude of the step is also $50 \%$ above the nominal value. The voltage $\mathrm{Vc}$ is sensitive to the actuator only during a transient period. The time response is almost 0.7 second. 

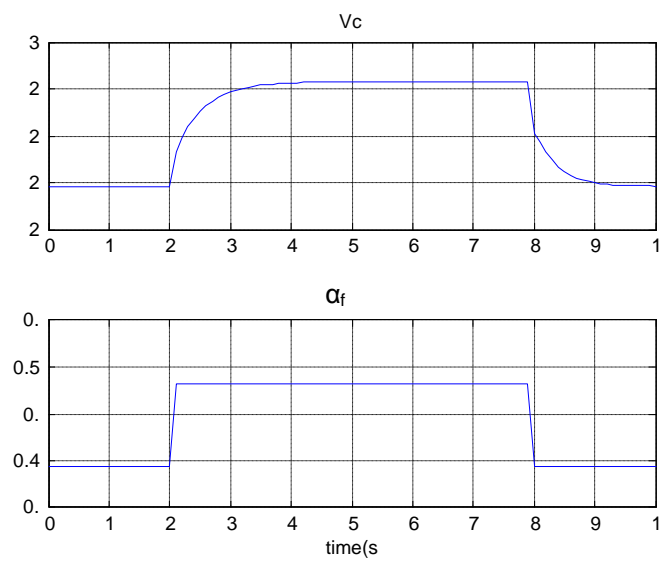

Fig. 3. Response time of fuel cell on a step on $\alpha_{\mathrm{fc}}$
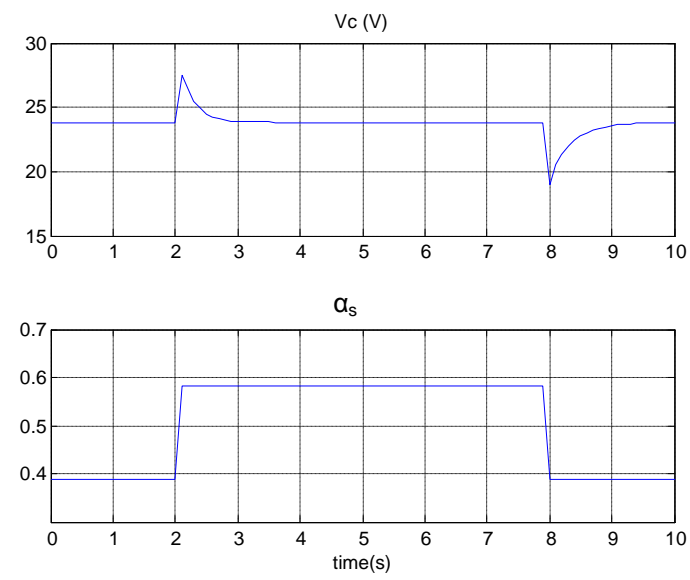

Fig. 4. Response time of fuel cell on a step on $\alpha_{\mathrm{sc}}$

As it can be seen from the above Figures 2 to 4, the system is reacting as expected: the supercapacitor is able to compensate the transient responses that the fuel cell can't handle. Further on, the management of both actuators will be held by the control strategy.

\section{Predictive Control StRAtegy}

\section{A. Non-linear Model Predictive Control Strategy}

A one-loop control strategy is carried out. The control law includes the strong non-linearities of the system behavior thanks to the previous model which becomes:

$$
\begin{aligned}
& \left\{\begin{array}{l}
\dot{x}=f(x, u, w) \\
y=V_{c}
\end{array}\right. \\
& \text { with } \mathrm{x}=\left[\begin{array}{llllll}
\mathrm{V}_{\mathrm{cc}} & \mathrm{V}_{\mathrm{ca}} & \mathrm{I}_{\mathrm{fc}} & \mathrm{I}_{\mathrm{sc}} & \mathrm{V}_{\mathrm{sc}} & \mathrm{V}_{\mathrm{c}}
\end{array}\right]^{\mathrm{T}} \\
& \mathrm{u}=\left[\begin{array}{ll}
\alpha_{\mathrm{fc}} & \alpha_{\mathrm{sc}}
\end{array}\right] \\
& \mathrm{w}=\left[\mathrm{I}_{\text {load }}\right]
\end{aligned}
$$

where $\mathrm{I}_{\text {load }}$ is a measurable disturbance and the control inputs are $\alpha_{\mathrm{fc}}$ and $\alpha_{\mathrm{sc}}$ are the converter duty cycles for the fuel cell and the supercapacitor respectively.

The main objective of the control law is to ensure the voltage $\mathrm{Vc}$ at the output of the system in accordance with the load demand and to enable efficient switching between the fuel cell and the supercapacitor.

The control is implemented in the aim of controlling the value of the output voltage $(\mathrm{Vc})$ around a set point (Vref) despite changes in the load value. To ensure that there is no divergence between the setpoint and the value of the output voltage, a cost function is minimized along a moving horizon and the suitable action is taken. In the classical NMPC approaches, the cost criterion to be minimized is:

$$
\mathrm{J}(\mathrm{x}, \mathrm{u})=\int_{\mathrm{t}}^{\mathrm{t}+\mathrm{Tp}}\left\|\mathrm{V}_{\mathrm{c}}(\tau)-\mathrm{V}_{\mathrm{ref}}\right\|^{2} \mathrm{~d} \tau
$$

where $\mathrm{Tp}$ is the prediction horizon and $\mathrm{V}_{\text {ref }}$ the reference value.

The actuator values are in the range [0 1]. The limitation on the harmful transient peaks on $\mathrm{I}_{\mathrm{fc}}$ can be managed as hard constraints on its maximal value and on the rate variations and will be discussed in the sequel. The constraints are summarized below:

$$
\begin{aligned}
& 0 \leq \alpha_{\mathrm{fc}} \leq 1 \\
& 0 \leq \alpha_{\mathrm{sc}} \leq 1 \\
& 0 \leq \mathrm{I}_{\mathrm{fc}} \leq \mathrm{I}_{\mathrm{fc} \max }
\end{aligned}
$$

As the system is non-linear, a quadratic programming algorithm has been used to solve this problem. One limitation of the method is the time consuming of the algorithm which is due to the algorithm, especially when the number of constraints increases. In addition, the constraint on the stack current is handled as a hard constraint that can never be exceeded. This is a strong limitation as the best strategy would be to maintain the current mainly in an operating range and let sometimes let the limitation be exceeded in a very short period of time to insure the voltage demand. We propose in the sequel a new strategy to solve the NMPC problem.

\section{B. Proposition of a new algorithm}

\section{1) Fastening the algorithm}

Using Non-linear MPC, the number of iterations that may be needed to reach a sufficiently good solution to the control problem may be beyond what is reasonably possible to achieve in the available computation time. The research for solutions is presently an active research field [8-12]. We consider here a method which is partly issued from [12] and which is well suited for such a system that shows fast dynamics and for which the control law handles a lowdimensional control parameterization. 
The computational effort during a single sampling period is mainly due to the loop needed to solve the QP problem with constraints on the actuators, which lead to compute many times the model. In this article the problem is transformed and detailed below.

Given a set of possible control inputs:

$$
\begin{gathered}
\alpha_{\mathrm{fc}}=\alpha_{\mathrm{fc} \_ \text {min }}: \delta_{\mathrm{fc}}: \alpha_{\mathrm{fc} \_ \text {max }}, \\
\alpha_{\mathrm{sc}}=\alpha_{\mathrm{sc} \_ \text {min }}: \delta s_{\mathrm{c}}: \alpha_{\mathrm{sc} \_ \text {max }},
\end{gathered}
$$

where $\delta_{\mathrm{fc}}$ is the interval step of $\alpha_{\mathrm{fc}}$ and $\delta_{\mathrm{sc}}$ is the interval step of $\alpha_{\mathrm{sc}}$.

The algorithm consists then in computing $\mathrm{J}(\mathrm{x}, \mathrm{u})$ for all the combinations of $\left(\alpha_{\mathrm{fc}}, \alpha_{\mathrm{sc}}\right)$. The control values to be applied are given by the minimum for $\mathrm{J}(\mathrm{x}, \mathrm{u})$.

The solution is non-optimal but it is obtained with a predictable computing time. The precision of the method is related to the interval steps $\delta_{\mathrm{fc}}$ and $\delta_{\mathrm{sc}}$, as well as the ranges $\left[\alpha_{\min } ; \alpha_{\max }\right]$. Thus a compromise between precision and computation time may be obtained for each application.

\section{2) Constraints management}

Because there is now no optimization algorithm, the management of the constraints is therefore different from the classical NMPC and must not affect the computing time. To find the control $\mathrm{u}$ that minimizes $\mathrm{J}(\mathrm{x}, \mathrm{u})$ and that satisfies the constraints, an additional term $\mathrm{c}$ penalizing constraint overtaking may be added to $\mathrm{J}(\mathrm{x}, \mathrm{u})$.

The dynamical constraint to be minimized can be written:

$$
\mathrm{c}=\max \left(\left(\mathrm{I}_{\mathrm{fc}}-\mathrm{I}_{\mathrm{fc}}^{\max }\right), 0\right)
$$

The problem leads to the following form of the modified cost function:

$$
J^{\prime}(x, u)=\int_{t}^{t+T p}\left\|V_{c}(\tau)-V_{\text {ref }}\right\|^{2}+\eta\|c\|^{2} d \tau
$$

where $\eta$ is a penalty that is chosen arbitrarily high.

Except for the saturation constraints on the actuators that have to be treated as hard constraints (their violation is physically impossible), the constraint on the fuel cell current can be viewed as a soft constraint. This means that constraint violation may be accepted for short amounts of time, but that most of the time the fuel cell current value is guaranteed to stay at a healthy value.

Beside this physical argumentation, the use of soft constraints is almost unavoidable from a computational point of view and especially for the problem under study. Indeed, due to the presence of unmodeled disturbances dynamics (due to the multi-physic nature of the fuel cell), the very existence of future control sequence that enhances the satisfaction of this output constraint cannot be guaranteed. In this case, the use of hard constraints may lead to a rigorously unfeasible optimization problem.

\section{SIMULATION RESULTS}

\section{A. Classical NMPC Control Strategy}

A classical Non-linear Model Predictive Control (NMPC) has been carried out for this system. The advantage is that the non-linear model is used to predict the behavior of the system. The main drawback is that the simulation time, correlated to the minimizing algorithm of the cost function, is uncontrolled. The only constraints that have been programmed are on the actuators (which are between 0 and 1) and on the fuel cell current $\mathrm{I}_{\mathrm{fc}}$ (which is positive). Thus a Matlab® function "fmincon" has been used, with a Least Square Algorithm which satisfies bounds at all iterations. Finite differences, used to estimate gradients, are centered, which takes twice as many function evaluations as the standard ones but is more accurate.

The simulation has been carried out with the minimization of the cost $\mathrm{J}$ from equation 12 . The prediction horizon $T_{p}$ has been chosen together with the time step $\tau$ thanks to the previous model simulations and after some trial and errors. As the time response is about 1 second, the time step $\tau$ is assumed to be ten times less, namely $\tau=0.1 \mathrm{~s}$. The prediction horizon has to fit the first stabilized values after the transient response in order to avoid oscillations (if too short) or long time response (if too long). A value of $2 \mathrm{~s}$ has thus been taken for $\mathrm{T}_{\mathrm{p}}$.

The controlled system has been simulated in a first period for voltage reference tracking ( $20 \%$ positive step at time $4 \mathrm{~s})$ and in a second period for a load change (50\% positive current step from time $10 \mathrm{~s}$ to $14 \mathrm{~s}$ ), which is assimilated to a disturbance. Figure 5 shows the closed-loop evolution of the system under the predictive control law without physical constraints on the fuel cell current (maximal value or rate). In the top figure, the behavior of the output voltage $\mathrm{V}_{\mathrm{c}}$ is convenient: the voltage reacts immediately after the reference change with a slight delay which correspond to the time step $\tau$ and returns to the reference value after the load changes. However, the behavior of the fuel cell current $I_{\mathrm{fc}}$ is rather unsuitable due to the severe peaks that are really harmful for the fuel cell. To tackle this issue, constraints on the fuel cell current have been added.

To prevent a premature deterioration of the fuel cell, the maximal value and the rate of the fuel cell current $I_{\mathrm{fc}}$ are respectively limited to $120 \mathrm{~A}$ and $1.5 \mathrm{~A}$. These constraints can be handled by the Matlab® function "fmincon", and are thus "hard constraints" as they can never be exceeded.

Figure 6 displays the results. This time, the behavior of the fuel cell current is good. The effect of the modification of the computer programming can be seen only on the reactions of the currents and on the behavior of the actuators.

However the time during which the effect of $\mathrm{I}_{\text {load }}$ changes is visible is rather long on the output (about $2 \mathrm{~s}$ at time 10s). Similarly, the computing time is unreasonably long: 4376s, that is more than one hour with a standard Personal Computer. 

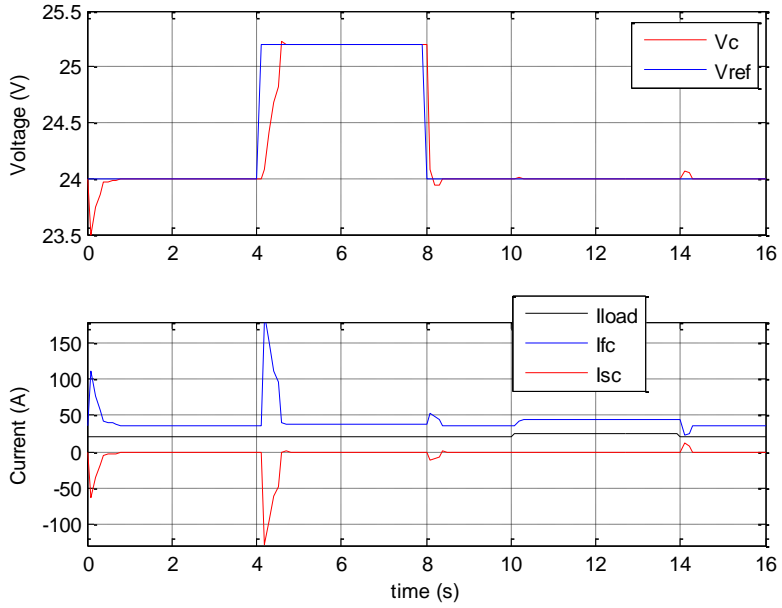

Fig. 5. Behavior of the system with NMPC and no $\mathrm{I}_{\mathrm{fc}}$ current limitation
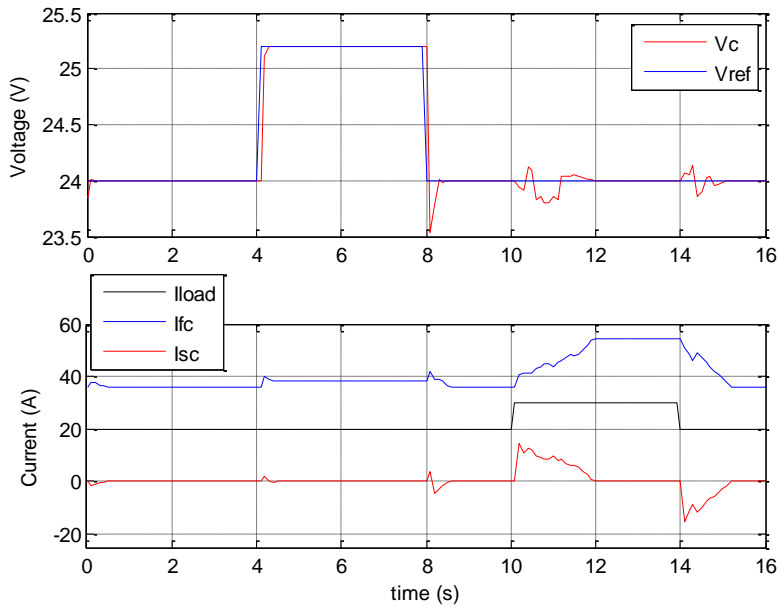

Fig. 6. Behavior of the system with NMPC and $\mathrm{I}_{\mathrm{fc}}$ current limitation

\section{B. Proposed algrorithm}

Here we use the proposed algorithm detailed in Section III.C. A novelty compared with classical NMPC is the discretization of the control inputs. Thus, it requires the adjustment of the interval steps $\delta_{\mathrm{fc}}$ and $\delta_{\mathrm{sc}}$, as well as the ranges $\left[\alpha_{\min } ; \alpha_{\max }\right]$ for each one. A compromise between precision and computation time has to be obtained for this application.

To avoid a too long simulation time, only 9 values are taken for $\alpha_{\mathrm{fc}}$ and 3 for $\alpha_{\mathrm{sc}}$. The results are shown in Figure 7. The reference voltage is slightly missed, which means that the voltage interval step $\delta_{\mathrm{sc}}$ has to be refined. However, the current behavior is smoother than in Figure 6 which shows the interest of this approach.

The interval step $\delta$ imposes an actuator step during the time step $\tau$. Both time and interval steps have to be sufficiently short in order to prevent from transient effects that may induce visible fluctuations. In the purpose of a better
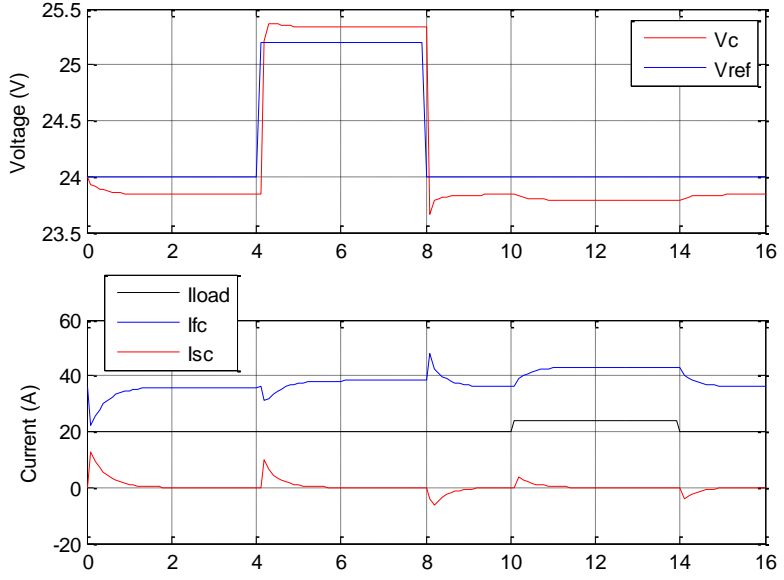

Fig. 7. Behaviour of the system with the new MPC algorithm, with 9 values for $\alpha_{\mathrm{fc}}$ and 3 for $\alpha_{\mathrm{sc}}$.
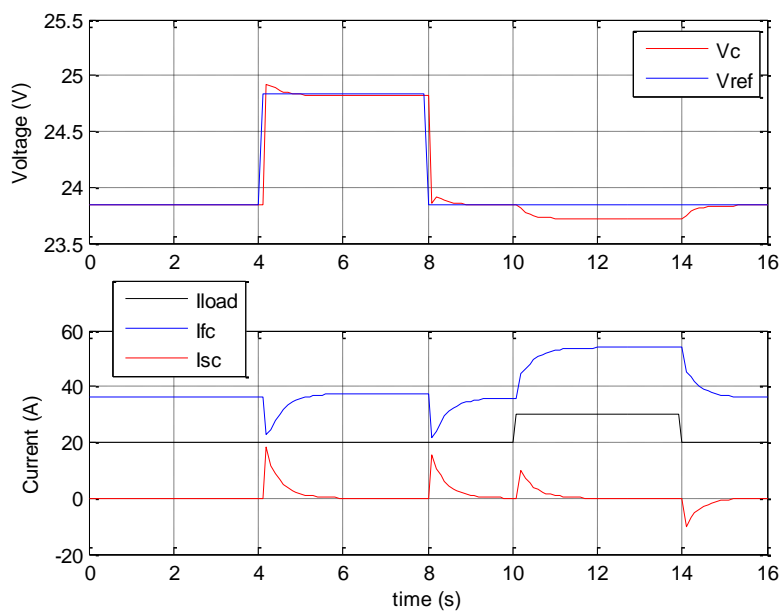

Fig. 8. Behaviour of the system under the new MPC algorithm, and with 9 values for $\alpha_{\mathrm{fc}}$ and 9 for $\alpha_{\mathrm{sc}}$. Range 10\% (elapsed time: 311 seconds)

output precision, we have chosen a range of $\pm 10 \%$ of the nominal value, with interval steps nearly $0.01 \quad\left(\delta_{\mathrm{fc}}=0.01115\right.$ and $\delta_{\mathrm{sc}}=0.0096875$ ). For each time step, 9x9 computations are thus carried out.

The resulting computing time is then about one hour, which is nearly the same as for the classical NMPC. So we had to find a way to fasten the algorithm. To let the tuning of the parameters free for performances purposes, the algorithm has been modified so as to update the actuator values only during the needed periods. The input variables are thus adjusted only if a sufficiently important cost value variation occurs. This algorithm becomes then really efficient, as the computations are performed only during the transient periods. Thus the computation times decrease up to about 300s, which is reasonable without getting a compromise on the quality of the results.

The next improvement is the prediction horizon Tp. This parameter insures the closed-loop stability: if its value is too 
small, the output voltage fluctuates without stabilizing, and if too long the cost function may not change significantly with the actuators variations and the computation time will increase. The prediction horizon $\mathrm{Tp}$ is $5 \mathrm{~s}$.

Figure 8 illustrates the results obtained with the new algorithm. The length of the prediction horizon has been shorten to $1 \mathrm{~s}$, in comparison to $5 \mathrm{~s}$ for the previous simulation (Figure 7), without any loss of accuracy. Indeed, the program improvement contributes to the closed-loop stabilization. Figure 8 displays an accurate voltage reference tracking, but the effects of load changes ( $\mathrm{I}_{\text {load }}$ step at time 10s) are visible on the output voltage. In fact the control actuators don't react to the load changes and what can be seen is a sort of "open-loop" behavior. To overcome this drawback, the threshold value of the cost function variation to be taken into account has been reduced, and the new results are presented in Figure 9.

In Figure 9, some fluctuations are visible before stabilization. Thus, a look at the actuators changes might be interesting and can be seen in Figure 10. Thus the visible fluctuations on the currents are due to the supercapacitor actuator $\left(\alpha_{\mathrm{sc}}\right)$ changes. Additionally, the actuator reaches its upper limit. Of course these results can be further improved and we work on this issue right now. For example the interval step $\delta$ can be reduced, but as the min-max interval has also to be improved, it will increase the computation time. The other possibility is to reduce the time step $\tau$, which will smooth the curves. Both of these issues are studied right now.

\section{CONCLUSION}

This paper has dealt with the control of a hybrid fuel cell / supercapacitor power generation system. A new algorithm has been proposed so as to limit the computation time while keeping the nonlinear behavior of the system. To reach this goal, some tunings that are specific to the application have been carried out. This means that an accurate knowledge of the system behavior and of its use must be known. To make this development stage easier, it would be interesting to develop a specific methodology. The benefits of this control algorithm are however obvious, as the fuel cell and the supercapacitor are better managed. The constraint management is equally more relevant without penalizing the computing time. Controllability studies are on the way to improve the performance.

\section{References}

[1] Azib, O. Bethoux, G. Remy, C. Marchand and E. Berthelot,"An Innovative Control Strategy of a Single Converter for Hybrid Fuel Cell/Supercapacitor Power Source", IEEE Transactions On Industrial Electronics, Vol. 57, No. 12, pp.4024-4031, December 2010.

[2] Thounthong P., P. Tricoli, B. Davat, "Performance investigation of linear and nonlinear controls for a fuel cell/supercapacitor hybrid power plant", Electrical Power and Energy Systems, Vol. 54, pp. 454-464, 2014

[3] El Fadil H., F. Giri,J. M. Guerrero, and A. Tahri," Modeling and Nonlinear Control of a Fuel Cell/Supercapacitor Hybrid Energy Storage System for Electric Vehicles", IEEE Transactions On Vehicular Technology, Vol. 63, No. 7, September 2014
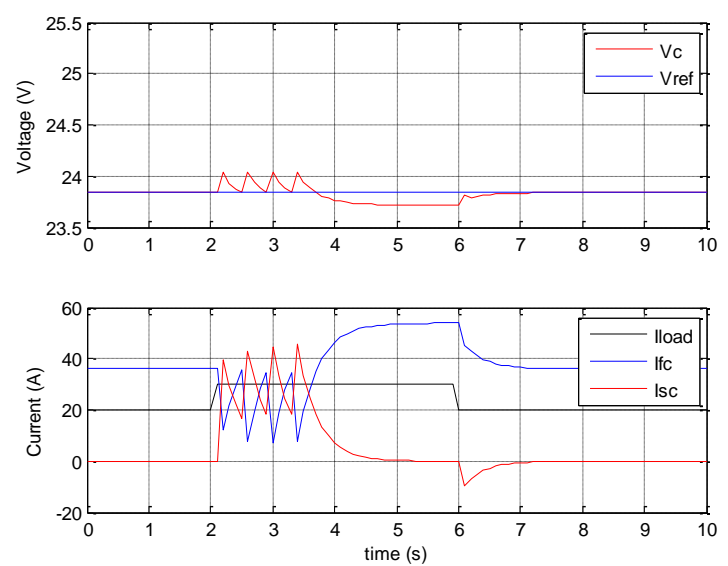

Fig. 9. Effect of load changes on the system

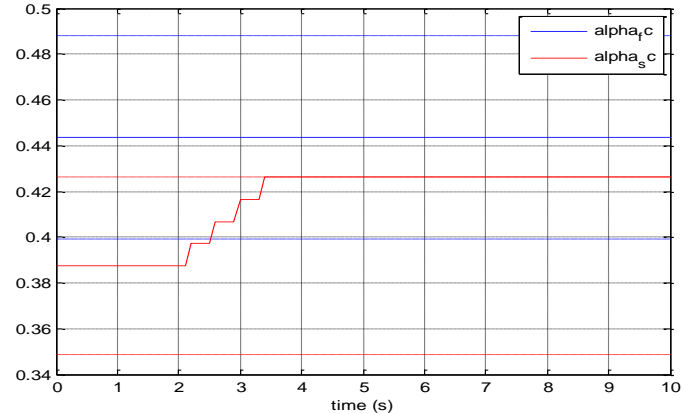

Fig. 10. Actuators behavior for load changes on the system (upper and lower limits in dash lines)

[4] Chen Q., L. Gao, R. A. Douga, S. Quan,” Multiple model predictive control for a hybrid proton exchange membrane fuel cell system", Journal of Power Sources, Vol. 191, pp.473-482, 2009

[5] Bambang A.R.T., A.S. Rohman,, C.J. Dronkers, R. Ortega, and A Sasongko," Energy Management of Fuel Cell/Battery/ Supercapacitor Hybrid Power Sources Using Model Predictive Control", IEEE Transactions On Industrial Informatics, Vol. 10, No. 4, November 2014

[6] Hernandez-Torres D., D. Riu, O. Sename, F. Druart, "A robust multivariable approach for hybrid fuel cell supercapacitor power generation system", European Physical Journal: Applied Physics, EDP Sciences, Vol 54 (2), 23407-p1/23407-p9., 2011

[7] Hernandez-Torres D., D. Riu, O. Sename, F. Druart, "Robust Optimal Control Strategies for a Hybrid Fuel Cell Power Management System", 36th Annual Conference of the IEEE Industrial Electronics Society (IECON'2010), Nov 2010, Phoenix, United States. 2010

[8] Yang X., L.T. Biegler, “Advanced-multi-step nonlinear model predictive control”, Journal of Process Control, vol. 23, 2013,pp. 1116- 1128

[9] Cai X., M.J. Tippett, L. Xie, J. Bao, "Fast distributed MPC based on active set method", Computers and Chemical Engineering, vol. 71, 2014, pp.158-170

[10] Biegler L.T., X. Yang, G.A.G. Fischer, Advances in sensitivity-based nonlinear model predictive control anddynamic real-time optimization, Journal of Process Control, 2015, In Press

[11] Lee J.H., Model Predictive Control: Review of the Three Decades of Development, International Journal of Control, Automation and Systems, vol. $9, \mathrm{n}^{\circ} 3,2011$, pp. 415-424

[12] Alamir M., "A framework for real-time implementation of lowdimensional parameterized NMPC”, Automatica, vol. 48, 2012, pp.198204 